\section{Why Choose Schottky Emission?}

First in a series of articles on the technology and benefits of Schottky emission. (Reprinted from FEl Focus on Components newsletter. Summer 1997)

Schottky emission is the predominant electron source technology in today's focused electron beams equipment including SEM, TEM, Auger systems, and semiconductor inspection tools. Because of its performance and reliability benefits, Schottky emission has largely replaced earlier source technologies based on either thermionic tungsten and $\mathrm{LaB}$, emission or cold-field emission. This article describes the Schottky emitter's benefits over other electron sources, explaining why so many manufacturers have adopted Schottky emission.

Many microscope and analytical applications in the semiconductor, materials, and life sciences require focused electron beams. Commercial manufacturers employ various electron lens designs depending on the application or available technology. Common objectives include high spatial resolution, rapid data acquisition, and reliable operation. Achieving these objectives requires an electron source with the following ideal properties:

- Small source size

- Low electron emission energy spread

- High brightness or beam current per solid angle

- Low short-term noise and long-term stability

- Simple and low-cost operation

In basic electron optics, the final probe size is mostly dependent on source demagnification and chromatic and spherical lens aberrations. Optics using high demagnification are complicated and more susceptible to lens aberrations unless small beam-defining apertures (BDA) are used. A small BDA reduces probe current to an unacceptable level. A high brightness electron source can be used with a small BDA to maintain reasonable probe

\section{Modern Coating Solutions for Today's EM Sample Prep Needs}

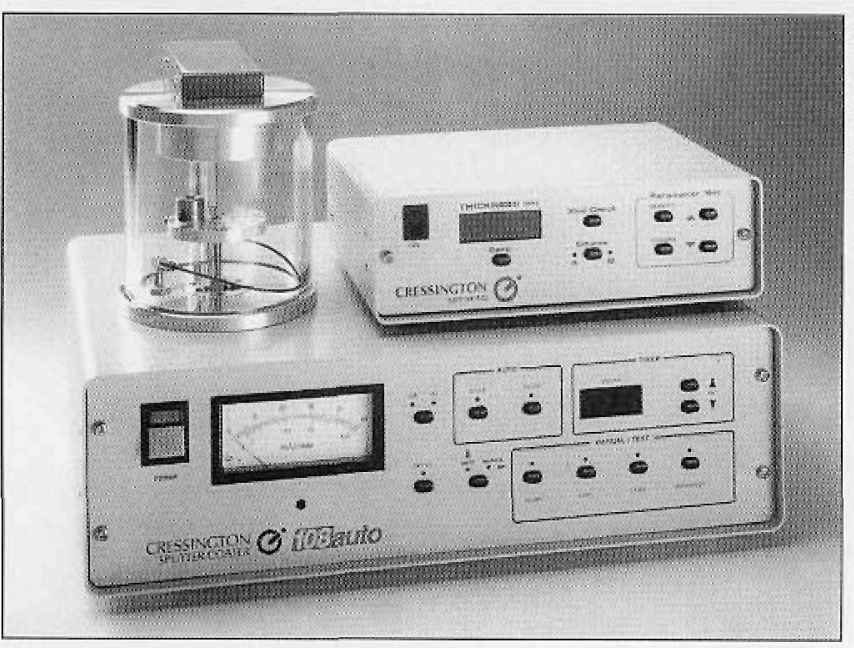

Compact modern desktop systems with fast cycle times. Carbon and sputtering systems for all SEM, FE-SEM and TEM applications.

\section{CRESSINGTON}

Cressington Scientific Instruments, Inc.

508 Thomson Park Drive, Cranberry Twp., PA 16066

TEL 800-755-1781 / 412-772-0220 FAX 412-772-0219

Website: www.cressington.com current. Additionally, a small source size relaxes demagnification requirements allowing a larger BDA, which simplifies the optical design. Conveniently, both Schottky and cold field emission provide small source size (1000 times smaller $\stackrel{0}{\circ}$ than thermionic emitters) and high brightness (100 times brighter than thermionic emitters)

In many electron lens optics designs, chromatic aberrations are more limiting to final beam size than spherical aberrations. The chromatic aberration $u$ magnitude is a function of the electron beam's energy spread. Energy spread is $\vec{s}$ the average difference of the electron energies in the beam. Schottky and cold field emission processes typically have lower energy spread than thermionic emission processes.

Schottky and cold field emission are superior to thermionic sources in terms of source size, brightness, and energy spread. Schottky emission is preferred $\frac{\overline{5}}{\bar{n}}$ over cold field emission due to its greater stability, simpler operation and lower $\vec{\pi}$ cost.

Operating at elevated temperatures $\left(1800^{\circ} \mathrm{K}\right)$ evaporates contaminants off the Schottky emitter, promoting long-term stability. Contaminants condense on the room-temperature cold field emitters disrupting emission stability. The need $\frac{2}{3}$ to periodically clean the cold field emitter by flash-heating interupts work in process.

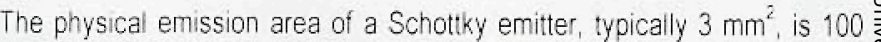
times greater than a cold field emitter. The small size of the cold field emitter makes it sensitive to natural contaminants in an electron column, resulting in high o frequency emission instability, i.e. noise. Noise reduces image quality and analysis accuracy. Schottky's large emission area and high temperature minimize the effects of contaminants.

Schottky emission vacuum requirements are less stringent than cold field emission vacuum requirements, which reduce equipment and maintenance costs. Also, Schottky emitter lifetimes are very long compared to other sources. Source replacement is both time-consuming and expensive

Table 1 reviews the key properties from the various electron sources Schotky emission most closely matches the ideal source properties. This is the reason so many manufacturers use Schottky emission in microscopes and analytical systems

Table 1: Comparison of electron emitters

\begin{tabular}{|l|l|l|l|l|}
\hline & Schottky & Cold Field & LaB $_{6}$ & Tungsten \\
\hline $\begin{array}{l}\text { Source } \\
\text { Si/c (nm) }\end{array}$ & 15 & 3 & $10^{4}$ & $>10^{4}$ \\
\hline $\begin{array}{l}\text { Energy } \\
\text { Spread (eV) }\end{array}$ & $0.3-1.0$ & $0.2-0.3$ & 1.0 & 1.0 \\
\hline $\begin{array}{l}\text { Brightness } \\
\text { (Aicm'SR }\end{array}$ & $5 \times 10^{5}$ & $10^{5}$ & 10 & $10^{6}$ \\
\hline $\begin{array}{l}\text { Short-Term } \\
\text { Beam Cur- } \\
\text { rent Stabil- } \\
\text { ity (\%RMS) }\end{array}$ & $<1$ & $4-6$ & $<1$ & $<1$ \\
\hline $\begin{array}{l}\text { Operating } \\
\text { Vacuum } \\
\text { (Torr) }\end{array}$ & 10 & 2000 & 1000 & 100 \\
\hline $\begin{array}{l}\text { Typical } \\
\text { Service Life } \\
\text { (hrs) }\end{array}$ & 6000 & 10 & $10^{5}$ \\
\hline
\end{tabular}




\section{Ready for a change of environment?}

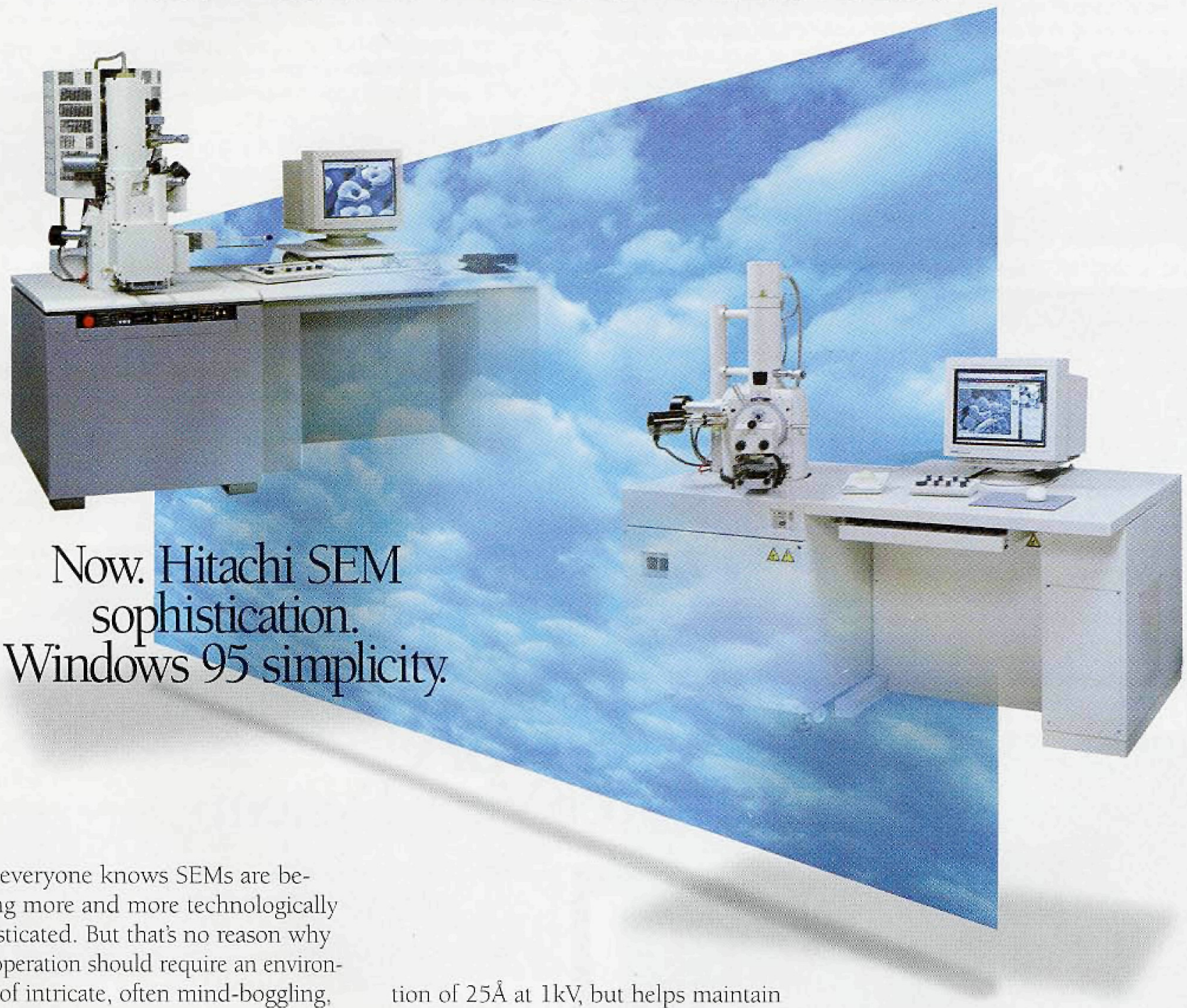

Sure, everyone knows SEMs are becoming more and more technologically sophisticated. But that's no reason why their operation should require an environment of intricate, often mind-boggling, challenges.

Enter Hitachi's new S-4700 and S-3500N SEMs, which replace all that operational complexity with the easy familiarity of Windows ${ }^{\mathrm{TM}} 95$ control. So anyone who's ever used a Windowsbased PC can - with a near-zero learning curve-take over their operation. And how's this? To keep die-hard traditionalists just as excited, these SEMs can come set up for convenient switching to conventional control as well.

Our S-4700 FE SEM and S-3500N Variable Pressure SEM offer even more to be excited about. Like superior resolution. The S-4700's new objective lens, for example, not only contributes to a resolu- tion of $25 \AA$ at $1 \mathrm{kV}$, but helps maintain that high resolution even when studying large samples at high tilt angles and at long working distances. Further, both instruments are available with our $\mathrm{Hi}$ Mouse feature, for operating EDX systems right from the SEM. (In fact, the S-4700's analytical mode permits EDX operation concurrent with high-resolution imaging.) And, with our Rapid Image Shift Movement (RISM) capability, you'll have the fastest, most precise specimen navigation ever.

So. Super performance made super easy. It's surely a refreshing environment for SEM microscopy. And just as surely, you'll want details on these breathrough SEMs. You can get them easily by phone or E-mail, or by visiting our Web site which, of course, you'll very likely do via a friendly Windows environment.

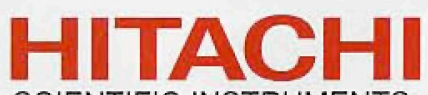

SCIENTIFIC INSTRUMENTS

Nissei Sangyo America, Ltd.

755 Ravendale Drive

Mountain View, CA 94043

(800) $227-8877$

E-mail: sidsales@nissei.com www.nissei.com

25 West Watkins Mill Road Gaithersburg, MD 20878 (800) 638-4087

Windows is a registered trademart of Mictosoft Corporation 